\title{
طَبَقَات الحُقََّّاظ
}

\section{لملال الدِيّن السِيَيُوطِيّ}

اهتمت الحضارة الإسلامية اهتماماً عظيماً بتدوين التاريخ -بِشِقََّّه: تاريخ الحوادث وتاريخ الرجال-

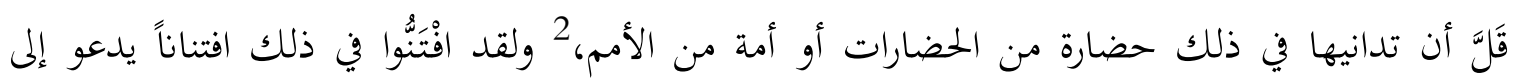
الدهشة والإعجاب، فألفوا في التاريخ السياسي الأسفارَ الطوال، وبسطوا القول في الحديث عن الملوك والخلَفاء، والأفراد، والحروب، ومظاهر الحضارة، ودرسوا بجتمعاقم من النواحي المختلفة، كما صنفوا في تاريخ البلدان، وترجموا من وَرَدها من الصحابة والتابعين، وتراجم من نشأ فيها وتوطنها ونُسِبَ إليها أو إلى نواحيها، ومَن دخلها من غير أهلها غازياً أو تاجراً أو طالباً للعلم.

ومما يدعو إلى الإعجاب والإكبار أن علماء المسلمين ألفوا في طبقاتٍ شتى من الناس على اختلاف تخصصاقم واهتماماهم وابتحاهاةم وصِفَاقِم، ولقد كان رُواة الحديث مِن هؤلاء الذين عُني بكم فريقُ من المصنفين عناية خاصة، بل ظهرت عناية المسلمين بتراجم هؤلاء الرجال منذ العصر الأول للإسلام، فتحدثوا عن فضائل بعض الصحابة مما مُلئت به كُتب الحديث، وكان هذا داعيًا للمؤرخين بعد ذلك لأن يحتذوا هذا الحذو ويقفوا على فضائل التابعين ومن بعدهم.

ولقد كان من نتائج اتساع الحركة العلمية وكثرة رواية الحديث أن رأى العلماء أنفسهم بين أصناف متعددة من الرواة، فبحثوا عن كل راوٍ وحللوه، وتعددت الآراء المختلفة في التجريح والتعديل، فجُمِعَت رَت الأخبار في نقد الرواة وبيان حالهم من حيث قبول عدالتهم وضبطهم، ودونت سيرته ومولده ووفاته ورحلته وشيوخه وتلاميذه ومسموعاته ومروياته ومؤلفاته -إن كانت له مؤلفات- ومدى دقته في الرواية ومدى

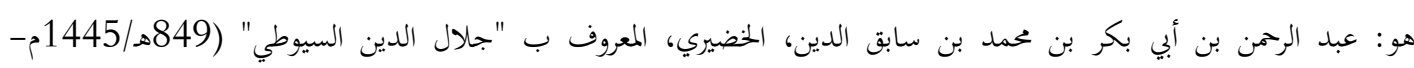

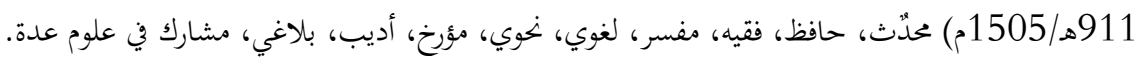

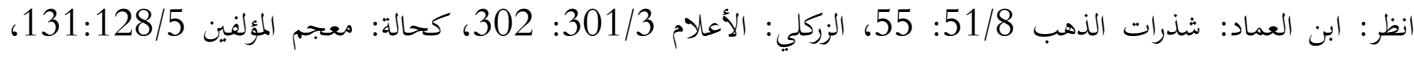

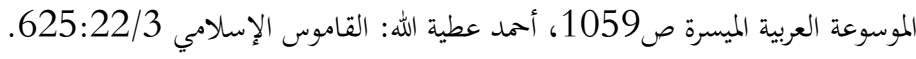
2 3 
اعتماده في الرواية على الحفظ أم الكتاب، ومقياس تورعه وتدقيقه في رواية ما يحفظ، إلى غير ذلك، فعلوا

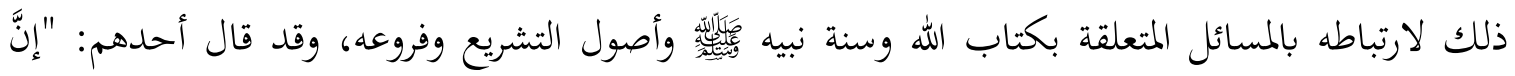

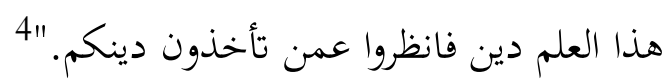

وقدمت الحضارة الإسلامية بذلك بين يدي النقد التاريخي عملا قيما لا يعرف له الناس مثيلاً في آداب الأمم الأخرى. وقد رُتبت معظم الكتب التي ألِّفَت في هذا الميدان إما طِبْقاً لأجيال المحدثين والرواة، أو طبقاً لمواطنهم وبلداهم، أو طبقاً للترتيب الهجائي لأسمائهم. وكتاب "طبقات الحفاظ" للحافظ (خاتمة الحُعَّاظ) جلال الدين السيوطي، من هذه المؤلفات التي رُيْبِّت التراجم فيه طبقاً لأجيال المحدثين وطبقاقم.

و"الحافظ" في اصطلاح المحدثين هو من توسع في رواية الحديث ومعرفة فنونه بحيث يكون ما يعرفه من الأحاديث وعللها أكثر مما يجهل، وقد حدده بعض أهل العلم بجفظ 100.000 حديث رواية ودراية

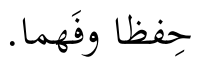

بَتَى السيوطي كتابه على كتاب "تذكرة الحفاظ"5 للحافظ شمس الدين الذهبي (- 748هـ| 1348م) 6 التي احتلت أهمية كبيرة في التاريخ العلمي عند المسلمين، وبنى عليها الكثيرون مؤلفات أُخرَ طلبا

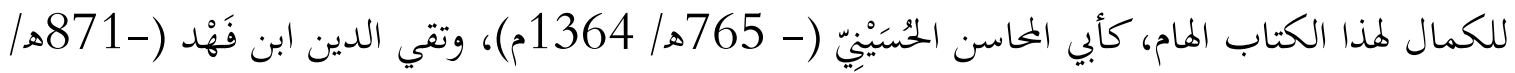

هذا قول منسوب إلى محمد بن سيرين وإلى مالك وغيرهما رحمهما الله تعالى، رواه عنهما وعن غيرها غير واحد من أهل العلم. انظر:

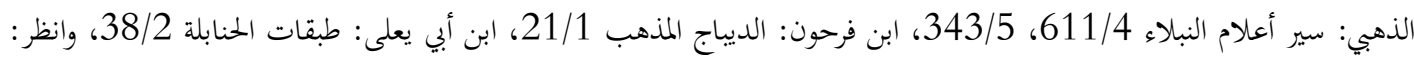
فتح المغيث للسخاوي 326/1 (ط. دار الكتب العلمية بيروت). نلفت نظر القارئ أن الكثير من السلف يعبر عنها باسم (طبقات الحفاظ) أيضاً، وهذا كثير في تعبير الحافظ ابن حجر عنها في لسان 5

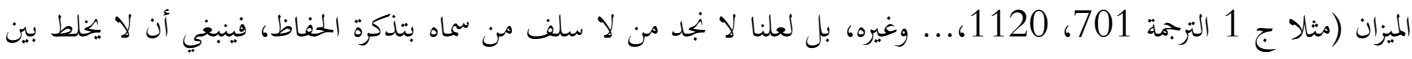

$$
\text { طبقات الحفاظ للذهبي وطبقات السيوطي. }
$$
سبق تقديم بحث عن تذكرة الحفاظ في هذا الباب. 
1467م)، 7 والسيوطي في ذَيٍْل صنفه يُكمل به الحفاظ من حيث وقف الذهبي إلى عصره، ثم عاد فضم إلى هذا الذيل تراجم أخر ولخص الكتاب، 8 فكان كتابه "طبقات الحفاظ."

لخص السيوطي في "طبقات الحفاظ" تذكركة الذهبي وأتمها إلى عصره، فجمع فيها من يُرْجَع إلى اجتهادهم في توثيق الرواة وجرحهم وتضعيفهم وتصحيح مروياقم، ورتبها على أربع وعشرين طبقة تبدأ بالطبقة الأولى طبقة الصحابة، وتنتهي الطبقة الأخيرة بشيخ الإسلام الحافظ الشهير ابن حجر العسقلاني المتوفى سنة 853هـ.

وقد احتوت كل ترجمة -غالباً- على اسم الحافظ وكنيته ونسبه، 10 ثم بيان أهم شيوخه، وأهم أصحابه، وبيان تاريخ وفاته -وقد يذكره سَنَة مولده أحياناً- وسياق بعض الأخبار عن الحافظ وشيء من مؤلفاته، وبعض أقوال العلماء فيه مما يكشف عن مبلغ علمه وعدالته، وشيء مما قيل فيه من عدالة وثناء، كل ذلك في إيجاز، فلم تتجاوز غالب تراجمه نصف الصفحة من القطع المتوسط. ولم يتقيد السيوطي بما في تذكرة الذهبي فجاء فيه بآراء ونقول ليست فيه، 11 فقد كان السيوطي يختار ويؤلف أيضاً، مما لا يُستغنى معله عن أي من الكتابين.

والكتاب يقدم للقارئ موسوعة صغيرة الحجم واسعة المجال عبر تسعة قرون من تاريخ الإسلام، تعرضت لأكثر من ألف ومائة من عيون أعلام الأمة، يقدم عن كل منهم فكرة موجزة مفيدة، ومثالاً يُحتذى.

7

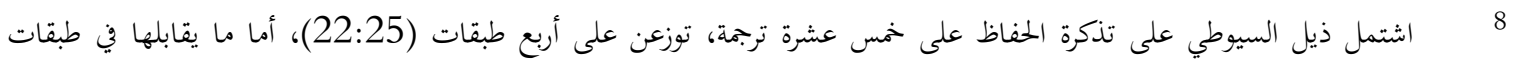

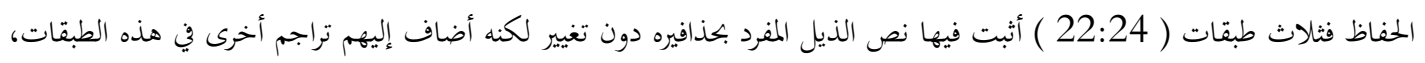

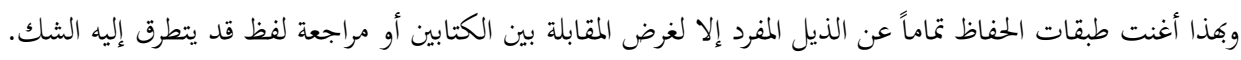

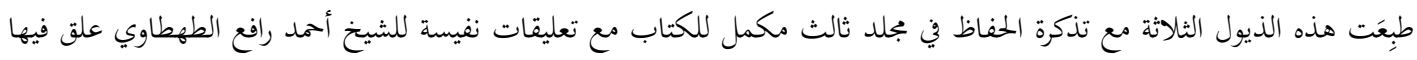
على الذيول الثلاثة. 10

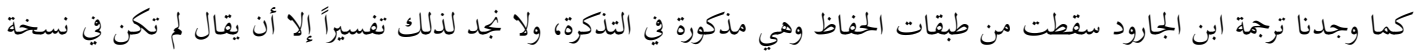
السيوطي من التذكرة، والمقام يحتاج لبحث. 
ولقد صَوََرَت "طبقات الحفاظ" مقاييس الثقافة في العالم الإسلامي في كل فترة من الفترات التي تناولتها، وابتحاهات العلماء الدراسية واهتماماهم العلمية في العلوم المختلفة، وطُرُق التدريس والإملاء والمناظرة والمذاكرة، والحلقات العلمية، وأماكن الدراسة في المساجد والجوامع والبيوت والربط، والمدارس المعنية بتدريس مذهب أو مذهَبَيْن أو المذاهب الأربعة في شتى أنحاء العالم الإسلامي. كما حَفِظَ لنا الحافظ السيوطي في كتابه عددا هائلاً من أسماء الكتب ووصفها مع تزويد الدارس بالمعلومات المتعلقة بها مما يمككن أن يشكل فهارس مكتبية (ببليوغرافيا) ضخمة. ولقد حَظيَ الكتاب بتحقيق علمي طيب قام به الأستاذ علي محمد عمر 12 الذي حقق الكتاب عن نسخة مكتبة مصطفى فاضل بدار الكتب المصرية (رقم 59 تاريخ م)، ونسخة المكتبة التيمورية (رقم 473 تاريخ -تيمور) فجاء تحقيقاً جيداً، أقام النص وصححه، وضبط كثيراً من أعلامه، وأدَّى للكتاب حقه، مذِِّّاً بفهارس الأعلام، والآيات القرآنية، والأحاديث النبوية، والأشعار، والقبائل والأمم والفِرَق، والأماكن والبلدان والمياه، والأيام والوقائع والحروب، والكتب، وقامت بنشره مكتبة وهبة، القاهرة، 1393هـ 1973م، في 717 صفحة، من القطع المتوسط، احتل نص الكتاب منه 548 صفحة.

أما نسخته الإلكترونية الصادرة ضمن أسطوانة (مكتبة التاريخ والحضارة الإسلامية) عن (شركة التراث، عَمَّان) والتي اعتمدت على طبعة (وترقيم صفحات) دار الكتب العلمية بيروت سنة 1403ه، فلا تعدو أن تكون عملاً تجارياً معيباً. 13

د. علي محمد عمر : محقق، اهتم بتحقيق التراث الإسلامي، وعمل بـ"مركز تحقيق التراث" بدار الكتب المصرية، امتازت أعماله التحقيقية

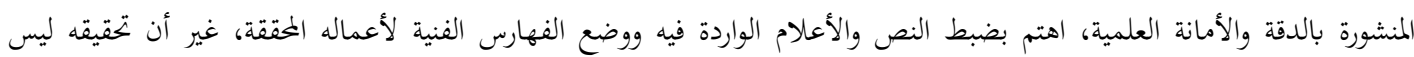

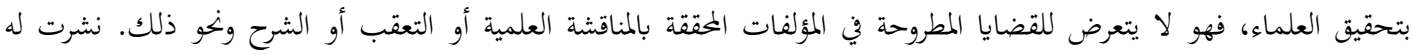

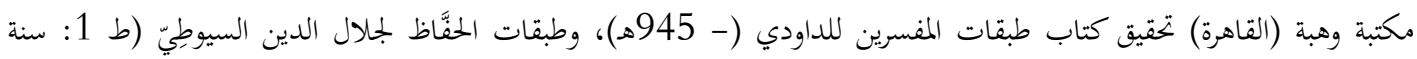

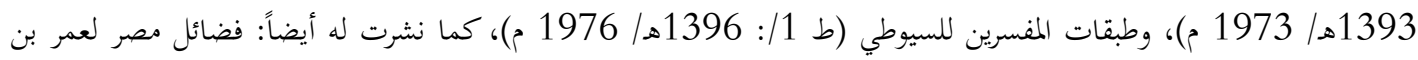

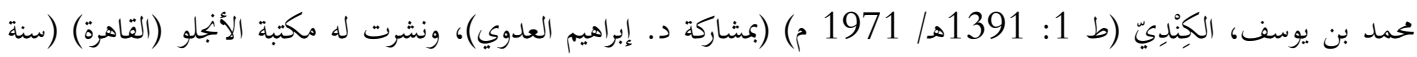

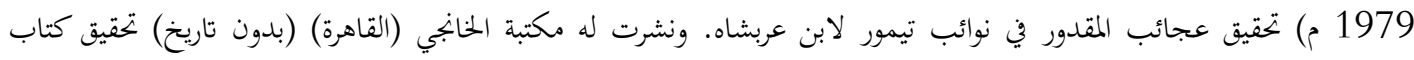

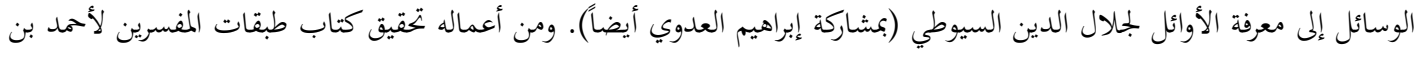
محمد الأدرنه وديّ (ق 11 11هـ). مثلا: من عجب أن يستكثر المسئول عنها -مثلا- مقدمة المؤلف والتي لم تزد على نصف صفحة فحذفوها! 